\title{
A EFETIVAÇÃO DO DIREITO SOCIAL AO TRABALHO NA PERSPECTIVA DOS DIREITOS FUNDAMENTAIS NA SOCIEDADE CONTEMPORÂNEA
}

\author{
THE ENFORCEMENT OF THE SOCIAL RIGHT TO WORK UNDER THE \\ PERSPECTIVE OF FUNDAMENTAL RIGHTS IN CONTEMPORARY SOCIETY
}

\author{
Suzéte da Silva Reis \\ Universidade de Santa Cruz do Sul - UNISC \\ sreis@unisc.br
}

Resumo: Pretende-se, com o presente artigo, identificar quais os entraves para a efetivação do direito social do trabalho na sociedade contemporânea. O texto constitucional de 1988 consagrou o direito ao trabalho como um direito social fundamental. No entanto e apesar da garantia constitucional, constata-se que a sua efetividade não está garantida, pois são recorrentes as situações de precarização e de violação a esse direito. Para responder ao problema de pesquisa: quais os entraves para a efetivação do direito social ao trabalho na sociedade contemporânea?, utilizar-se-á o método de pesquisa hipotético-dedutivo e como técnica de pesquisa será adotada a bibliográfica. Para a fundamentação teórica serão consultadas a literatura nacional e internacional especializada acerca da temática.

Palavras-chave: Contemporaneidade. Direitos sociais. Direitos fundamentais. Direito do Trabalho.

Abstract: The intention of the present article is to identify the obstacles to making effective the social right to work in contemporary society. The Brazilian Constitution of 1989 enshrined the right to work as a fundamental social right. However, and in spite of such constitutional safeguard, it's enforcement is not guaranteed, as situations of violation and precarization of such entitlement are recurrent. Hence, in order to address the following research problem: which are the obstacles for the enforcement of the social right to work in contemporary society?, a hypothetical-deducive method research method will be used, combined with the bibliographical research technique. The theoretical ground shall be composed by national and international specialized literature.

Keywords: Contemporaneity. Social Rights. Fundamental Rights. Right to Work.

\section{Para citar este artigo}

\section{ABNT NBR 6023:2018}

REIS, Suzéte da Silva. A efetivação do direito social ao trabalho na perspectiva dos direitos fundamentais na sociedade contemporânea. Prisma Jurídico, São Paulo, v. 19, n. 1, p. 40-59, jan./jun. 2020. http://doi.org/10.5585/prismaj.v19n1.14256. 


\section{Introdução}

O direito social do trabalho é um dos direitos fundamentais assegurados pelo texto constitucional brasileiro, conforme redação dos seus artigos $6^{\circ}$ e $7^{\circ}$. A partir da garantia prevista na Constituição Federal, várias outras normativas infraconstitucionais buscam garantir a efetivação do direito ao trabalho. A preocupação em assegurar a efetividade do direito social ao trabalho reside no fato de que é a partir do mesmo que os demais direitos sociais podem vir a se concretizar, na medida em que garante as condições de subsistência, participação social e no mundo produtivo.

Todavia, apenas a garantia formal não é suficiente para assegurar a garantia material. Prova disso são as reiteradas situações de trabalho precário, o trabalho em condições análogas a de escravo, o trabalho infantil, o trabalho informal, as taxas elevadas de desemprego, a desigualdade contratual entre empregados e empregadores, a desigualdade salarial entre homens e mulheres, dentre outras situações existentes e que afrontam a proteção constitucional e representam entraves à efetivação do direito social do trabalho.

Por outro lado, as transformações nos modos de produção, especialmente com a implementação da chamada indústria 4.0, provocam novas alterações nas relações laborais e nos contratos de trabalho. A exigência de determinadas competências e habilidades para se inserir no mundo do trabalho a partir da quarta revolução industrial, implica num novo perfil profissional. Com isso, determinados grupos de trabalhadores ficam à margem da proteção legislativa e das prerrogativas e garantias constitucionais.

No contexto desta pesquisa, adotar-se-á a concepção que define o direito social do trabalho como aquele direito que visa garantir à pessoa o exercício pleno das garantias asseguradas constitucionalmente, em particular aquelas elencadas no artigo $7^{\circ}$ da Constituição Federal de 1988. Assim, o direito social do trabalho inclui não apenas a garantia de acesso ao emprego formal, mas também a proteção contra a despedida arbitrária, as condições dignas de trabalho, a remuneração adequada, a observância das normas de medicina e de segurança do trabalho, incluindo os limites etários e de jornada de trabalho. Inclui ainda a proteção contra o trabalho precário e em condição análoga ao de escravo, a igualdade de gênero, o combate ao trabalho infantil e a todas as formas degradantes de trabalho.

Os direitos sociais nasceram em decorrência dos movimentos sociais, especialmente dos trabalhadores e trabalhadoras, que buscavam garantir melhorias nas condições de vida, já que os direitos civis e políticos, apesar de assegurarem a liberdade e o reconhecimento da pessoa perante o Estado, não garantiram a redução das desigualdades. 
Dentre os direitos sociais, o direito do trabalho assume significativa importância, pois o acesso ao mercado de trabalho possibilita que a pessoa possa prover o seu sustento e de sua família. Ademais, ser partícipe do sistema de produção assegura a ocupação de determinados espaços sociais que aqueles que estão à margem do mercado de trabalho não podem usufruir ou participar. Desse modo, é imprescindível garantir o acesso e a permanência de todos no mercado formal de trabalho, assim como garantir o exercício de condições dignas de trabalho e do direito de contratante em igualdade de condições com a outra parte.

As diretrizes traçadas pelo ordenamento jurídico brasileiro asseguram, no âmbito formal, a garantia de acesso, de permanência no mercado de trabalho e de exercício de condições dignas de trabalho. Entretanto, as contradições que permeiam a relação trabalho e capital, bem como as crises na atual conjuntura que demandam, por um lado, o aumento dos níveis de produtividade e, de outro, a redução dos custos de produção, provocam um deslocamento da centralidade do trabalho. Como consequência, há uma ruptura com o modelo de produção que, associada à reestruturação produtiva do capital, gera redução dos níveis de empregabilidade e de salários e compromete as possibilidades de emancipação pelo trabalho.

Com isso, verifica-se o trabalho exercido em condições precárias ou degradantes, com salários aviltantes e jornadas extenuantes, além da inobservância das normas de medicina e segurança do trabalho, que comprometem a integridade física e a saúde dos trabalhadores.

Outro aspecto que revela a (in) efetividade do direito social do trabalho diz respeito à desigualdade de gênero no ambiente laboral. Mesmo adentrado à segunda década do século XXI, mulheres com a mesma formação e exercendo as mesmas atividades recebem salários menores do que os homens nas mesmas condições. Para além da questão salarial, está a discriminação e a restrição, tanto no acesso quanto na ascensão na carreira, aos postos de comando. Na hierarquia funcional, a maioria dos cargos de direção e de gestão são ocupados por homens.

Nessa perspectiva, a presente pesquisa objetiva, a partir de uma análise acerca da temática, identificar quais os entraves para a efetivação do direito social do trabalho na sociedade contemporânea. Para responder ao problema de pesquisa - quais os entraves para a efetivação do direito social do trabalho na sociedade contemporânea? - adotar-se-á o método de abordagem hipotético-dedutivo. Como técnica de pesquisa, adotar-se-á a bibliográfica. Preliminarmente, tem-se como hipótese que os principais entraves à efetivação do direito social do trabalho na sociedade contemporânea, a partir da perspectiva dos direitos fundamentais, são a reestruturação produtiva do capital, as crises econômicas e o 
deslocamento da centralidade do trabalho, especialmente com o advento da quarta revolução industrial, ou com a chamada Indústria 4.0.

\title{
20 trabalho enquanto direito social fundamental
}

Os direitos fundamentais encontram-se positivados no ordenamento jurídico. São direitos garantidos e limitados no espaço e no tempo de determinado estado. Diferentemente dos direitos humanos, que são mais abrangentes e são reconhecidos na esfera internacional, os direitos fundamentais precisam estar positivados em um determinado ordenamento jurídico nacional.

Nesse sentido, importante é a lição de Sarlet (2010, p. 29):

\begin{abstract}
[...] é que o termo direitos fundamentais se aplica para aqueles direitos do ser humano reconhecidos e positivados na esfera do direito constitucional positivo de determinado Estado, ao passo que a expressão direitos humanos guardaria relação com os documentos de direito internacional, por referir-se àquelas posições jurídicas que se reconhecem ao ser humano como tal, independentemente de sua vinculação com determinada ordem constitucional, e que, portanto, aspiram à validade universal, para todos os povos e tempos, de tal sorte que revelam um inequívoco caráter supranacional (internacional).
\end{abstract}

Os direitos fundamentais são aqueles "reconhecidos como tal pelas autoridades, as quais se atribui o poder político de editar normas, tanto no interior do Estado quanto no plano internacional (COMPARATO, 2001, p. 56). Pode-se resumir dizendo que os direitos fundamentais são os direitos humanos reconhecidos e positivos em determinado estado.

Romita (2017, p. 49) reconhece o caráter histórico dos direitos fundamentais, afirmando que "pode-se definir direitos fundamentais como os que, em dado momento histórico, fundados no reconhecimento da dignidade da pessoa humana, asseguram a cada homem as garantias de liberdade, igualdade, solidariedade, cidadania e justiça".

No Brasil, a Constituição Federal de 1988 inaugurou uma nova fase, consolidando o Estado Democrático de Direito e demarcando o compromisso com o catálogo de direitos fundamentais. Os direitos sociais, dentre os quais se inclui o direito ao trabalho, encontram amparo constitucional no artigo $6^{\circ}$ e buscam assegurar a satisfação mínima das necessidades básicas da pessoa e a proteger a dignidade da pessoa humana.

$\mathrm{O}$ reconhecimento do trabalho como um direito fundamental está assegurado em diversos dispositivos constitucionais. Já no artigo I, inciso IV, IV os valores sociais do trabalho e da livre iniciativa são reconhecidos como fundamentos da República. $\mathrm{O}$ artigo $3^{\circ}$ elenca os objetivos fundamentais, dentre os quais, garantir o desenvolvimento nacional e 
erradicar a pobreza e a marginalização e reduzir as desigualdades sociais e regionais. Para que isso seja possível, o trabalho deve ser reconhecido e valorizado como fundamental. O artigo $6^{\circ}$ estabelece que são direitos sociais a educação, a saúde, a alimentação, o trabalho, a moradia, o transporte, o lazer, a segurança, a previdência social, a proteção à maternidade e à infância, a assistência aos desamparados e o artigo $7^{\circ}$ estabelece $\mathrm{o}$ rol de direitos aos trabalhadores rurais e urbanos.

No entanto, além do que dispõem os artigos que tratam dos direitos e garantias individuais, o trabalho é reconhecido no artigo 170, ao dispor que a ordem econômica, fundada na valorização do trabalho humano e na livre iniciativa, tem por fim assegurar a todos existência digna, conforme os ditames da justiça social, observados os seguintes princípios, dentre eles a busca do pleno emprego.

O princípio do pleno emprego está intimamente relacionado à efetividade do direito ao trabalho. Entretanto, a questão é complexa e não se pode confundir o direito fundamental ao trabalho com emprego. Ainda que a garantia de pleno emprego, sem dúvida, é essencial para o acesso ao mercado de trabalho e exercício do direito ao trabalho, por si só, não garante a efetividade deste direito fundamental. A proteção constitucional é mais ampla e contempla vários aspectos, incluindo a garantia de acesso e permanência no mercado de trabalho, bem como as condições dignas e a remuneração adequada, que são elementos essenciais da dignidade humana, que ocupa papel central no ordenamento jurídico brasileiro.

Conciliar esses preceitos em uma sociedade capitalista impõe desafios e implica na atuação ativa do Estado. A lógica capitalista é excludente e agressiva e representa uma luta constante entre os fatores de produção e o acúmulo de capital. No Brasil, a tentativa de intervenção ocorreu pela adoção de medidas como a reforma trabalhista, da previdência e gestão de cortes públicos (SILVA; BENACCHIO, 2019).

A valorização do trabalho humano e o reconhecimento do direito ao trabalho como um direito fundamental vinculam não apenas o Estado, mas também os privados, que devem respeitar os preceitos estabelecidos pelo texto constitucional, bem como as demais normas infraconstitucionais. Do contrário, tem-se a violação desse direito fundamental, o que se observa com as situações de trabalho precário, trabalho em condição análoga a de escravo e outras formas de subemprego.

Diante disso, cumpre assegurar a plena efetividade do direito ao trabalho. A posição que ocupam os direitos fundamentais na ordem jurídica representa os valores axiológicos que sustentam determinada sociedade, especialmente a dignidade humana. O trabalho, nessa perspectiva e na condição de direito social fundamental, deve ser efetivado a partir da 
efetivação do princípio do pleno emprego, por parte do Estado, bem como da observância dos seus preceitos pelos privados.

\section{A centralidade do trabalho}

O trabalho é a fonte de toda a riqueza. Contudo, ele é muito mais do que isso. Em uma breve revisão teórica, é possível constatar sua relevância. Para Engels (2014, p. 253), o trabalho "es la condición básica y fundamental de toda la vida humana"1, ou indo mais além, “debemos decir que el trabajo há creado al próprio hombre". ${ }^{2}$

O trabalho é uma categoria essencial para a compreensão das relações entre as pessoas e a natureza. Para Hegel (1992) o trabalho é uma ação intencional, consciente e reflexiva, através da qual o homem vence a tirania da natureza, na medida em que consegue satisfazer as necessidades individuais, utilizando-se do que a natureza oferece.

Para além da decodificação e utilização da natureza, o trabalho é o elemento central no estabelecimento da própria constituição social e das relações que se estabelecem a partir do trabalho. É a partir do trabalho que a pessoa toma consciência da sua própria existência, afirma seu domínio sobre a natureza e opera em favor da transformação das relações sociais (HEGEL, 1992).

O trabalho é essencial para a constituição da sociedade e da dignidade da pessoa. Para Weber (2004), a categoria trabalho ocupava um lugar central, exercendo um papel determinante na gênese do capitalismo moderno e na construção da noção moderna de trabalho. Do mesmo modo, Marx (1996) considerava o trabalho como uma categoria central para a compreensão da sociedade ocidental, pelo meio do qual o ser social conseguiu se impor sobre a natureza, reconhecê-la e transformá-la.

Além disso, Weber (2004) destaca que a relação entre trabalho e prosperidade estabelecida pelo protestantismo foi de significativa importância para o êxito do trabalho moderno. Ao difundir a ideia de que o trabalho é uma graça divina para o indivíduo, a religião influenciou sobremaneira a visão acerca da riqueza, afastando a ideia de pecado, pois a riqueza passa a ser considerada como resultado do trabalho. Desse modo, a teologia da prosperidade impulsionou a produção e o capitalismo.

\footnotetext{
1 "devemos dizer que o trabalho criou o próprio homem" (ENGELS, 2014, p. 253, tradução livre).

2 "é a condição básica e fundamental de toda vida humana" (ENGELS, 2014, p. 253, tradução livre).
} 
O trabalho tem papel de destaque na racionalidade capitalista, ao mesmo tempo em que a racionalidade estratégica do capitalismo desvincula o trabalho dos critérios de referência doméstica e de satisfação pessoal. Nesse sentido, verifica-se que

\begin{abstract}
O triunfo global do capitalismo é o tema mais importante da história nas décadas que sucederam 1848. Foi o triunfo de uma sociedade que acreditou que o crescimento econômico repousava na competição da livre iniciativa privada, no sucesso de comprar tudo no mercado mais barato (inclusive trabalho) e vender no mais caro. Uma economia assim baseada, e portanto repousando naturalmente nas sólidas fundações de uma burguesia composta daqueles cuja energia, mérito e inteligência elevou-os a tal posição, deveria - assim se acreditava - não somente criar um mundo de plena distribuição material, mas também de crescente felicidade, oportunidade humana e razão, de avanço das ciências e das artes, numa palavra, um mundo de contínuo e acelerado progresso material e moral (HOBSBAWN, 1979, p. 17).
\end{abstract}

Durkeim (2010), por sua vez, entende que o trabalho é essencial enquanto processo de interação, porque possibilitaria a produção de critérios de justiça e a integração dos trabalhadores à sociedade. $\mathrm{O}$ autor defende que a existência da sociedade somente é possível a partir de um determinado grau de consenso, a que chama solidariedade social. Essa solidariedade pode divide-se em mecânica e orgânica. Na primeira, há o compartilhamento dos mesmos valores sociais em relação às crenças religiosas e interesses materiais; na segunda, prevalecem mais os interesses individuais, característicos das sociedades mais complexas e atuais.

Ao tratar da divisão social do trabalho e da solidariedade dela decorrente, Durkeim (2010, p. 429) afirma que "ela cria entre os homens todo um sistema de direitos e deveres que os ligam uns aos outros de maneira duradoura". Afirma também o desenvolvimento do capitalismo contribuiu para a divisão social do trabalho, na medida em que os meios de produção foram se ampliando e exigindo funções mais especializadas e para o surgimento das sociedades com solidariedade orgânica.

Weber (2004), ao contrário, defende que as pessoas não agem influenciados por forças exteriores, mas sim que agem socialmente, levados por motivos racionais, emotivos e pelas tradições e costumes. As sociedades se formam, portanto, a partir das condições históricas. E, nas sociedades capitalistas, o trabalho adquiriu um papel central e fundamental.

Desde os primórdios o trabalho faz parte da vida humana. Inicialmente com o objetivo de assegurar a própria subsistência, os contornos do trabalho foram sendo alterados ao longo da história. Uma importante e significativa alteração foi decorrência da Revolução Industrial, que "criou uma categoria racional na ordenação política da sociedade além de transformar a 
liberdade em mera abstração, com a concentração das massas operárias sob o jugo do capital empregado nas grandes explorações com unidade de comando" (VIANNA et al, 2004, p. 33).

Entretanto, muito mais do que um meio de subsistência, o trabalho revela-se como elemento essencial para a emancipação do ser humano. Portanto, não “deve ser tratado como mera mercadoria, ou seja, ainda que sob a égide do capitalismo, as condições mínimas de dignidade para a pessoa do trabalhador devem ser garantidas pelo Estado e observadas pelos particulares" (BARBOSA, 2017, p. 241).

De lá para cá, a centralidade do trabalho ocupou diferentes posições e status. Todavia, em momento algum o trabalho perdeu a sua condição fundante. Para Süssekind (2006), o trabalho é o mais importante veículo de afirmação comunitária da grande maioria dos indivíduos que compõem a sociedade capitalista, além de representar um dos mais relevantes instrumentos de afirmação da democracia na vida social.

A valorização do trabalho e o seu reconhecimento como condição para a dignidade humana remete ao Cristianismo. Vianna e outros (2004) destacam que esses foram os fundamentos do Direito do Trabalho, que se consolidou somente séculos mais tarde, assegurando aos trabalhadores, além de um rol de direitos mínimos, a garantia de um trabalho digno.

Süssekind (2006), afirma que a dignidade pelo viés do trabalho é recente, tanto no plano individual quanto no plano da sua inserção familiar e social. Por essa razão, a "valorização do trabalho é um dos princípios cardeais da ordem constitucional brasileira democrática" (SÜSSEKIND, 2006, p. 146), que reconhece a essencialidade da conduta laborativa como instrumento para a afirmação do ser humano.

Partindo da mesma linha de entendimento, Delgado (2007) defende que a Constituição Federal reconheceu a centralidade do trabalho, tanto na vida pessoal quanto comunitária do indivíduo. Além disso, reconheceu o trabalho como condição de vida digna devendo, portanto, ser interpretado de forma indissociável da dignidade humana.

O trabalho tem como premissas a possibilidade de emancipação da pessoa e o crescimento econômico. Contudo, é preciso que as duas concepções estejam atreladas, pois é incompatível que a liberdade humana e o trabalho digno convivam com formas de desenvolvimento econômico predatórias. Muito pelo contrário: o crescimento econômico não pode servir para a precarização do trabalho e da condição humana. Porém, ao longo da história do trabalho, constata-se que nem sempre foi possível conciliar essas duas premissas.

As transformações no mundo do trabalho são inerentes à própria existência do trabalho. Marx (1996, p. 14) afirma que “a indústria moderna exige, por sua natureza, 
variação do trabalho, isto é, fluidez das funções, mobilidade do trabalhador em todos os sentidos".

Engels (2014, p. 271) enfatiza que

\begin{abstract}
Los hombres que em los siglos XVII y XVIII trabajaron para crear la máquina de vapor, no sospechaban que estaban creando un instrumento que habría de subvertir, más que ningún outro, las condiciones sociales em todo el mundo, y que, sobre todo en Europa, al concentrar la riqueza en manos de una minoria y al privar de toda propiedad a la inmiensa mayoría de la población, habría de proporcionar primero el domínio social y político a la burguesia y provocar después la lucha de clases entre la burguesia y el proletariado, lucha que solo puede terminar con el derrocamento de la burguesia y la abolición de todos los antagonismos de clase.
\end{abstract}

No entanto, a luta de classes não subsistiu e o modo de produção capitalista prevaleceu, tendo "como fonte de riqueza a exploração do trabalho, sendo, assim, logicamente contrário ao princípio da dignidade da pessoa humana" (BARBOSA, 2017, p. 236).

No modo de produção capitalista, que se desenvolveu e se expandiu pelo mundo a partir da constituição de métodos de produção da mais-valia (ALVES, 2011), as transformações são nitidamente delimitadas. O taylorismo, que surgiu no final do século XIX nos Estados Unidos caracterizava-se pela produção em massa de bens homogêneos e marcou o início do período da produção industrial. A organização do trabalho estava voltada à obtenção de grande produtividade, sendo que cada trabalhador era responsável por uma determinada tarefa na linha de produção.

Na sequência, o fordismo, no início do século XX, também assentado no modelo de produção em massa de um produto, acrescentou um novo elemento: o ritmo de trabalho, que no taylorismo era determinado pelo rendimento individual, passou a ser determinado pelo ritmo das máquinas e esteiras.

Já o toyotismo, também conhecido como acumulação flexível, difundiu-se pelo mundo a partir de 1970. Contrapondo-se aos modelos anteriores, no toyotismo o ritmo da produção era determinado pela demanda e pela organização horizontal do trabalho. O trabalhador não realizava apenas uma única tarefa na linha de produção, mas várias atividades. $\mathrm{O}$ trabalho em grupo objetivava a obtenção de um melhoramento contínuo dos produtos.

Alves (2011, p. 43) argumenta que o toyotismo - ou Sistema Toyota de Produção - é a “ideologia orgânica do novo complexo de reestruturação produtiva do capital que encontra nas novas tecnologias da informação e comunicação [...] a materialidade sociotécnica à nova produção de mercadorias". Esse sistema de produção influenciou fortemente o sistema de produção na atualidade. Ao romper com o modelo anterior e introduzir o conceito de 
eficiência na produção, percebe-se o aumento da desregulamentação das condições e dos direitos dos trabalhadores, particularmente com o aumento das terceirizações.

Delgado (2014) salienta que na terceirização o trabalhador é inserido no sistema produtivo de um terceiro, que é o tomador de serviço, sem que para tal trabalhador sejam estendidos os mesmos direitos e garantias trabalhistas dos empregados da empresa tomadora dos serviços, pois o vínculo formal é com a empresa intermediária. Assim,

\begin{abstract}
a terceirização provoca uma relação trilateral em face da contratação de força de trabalho no mercado capitalista: o obreiro, prestador de serviços, que realiza suas atividades materiais e intelectuais junto à empresa tomadora de serviços; a empresa terceirizante, que contrata este obreiro, firmando com ele os vínculos jurídicos trabalhistas pertinentes; a empresa tomadora de serviços, que recebe a prestação de labor, mas não assume a posição clássica de empregadora desse trabalhador envolvido. (DELGADO, 2014, p. 452).
\end{abstract}

Como consequência da expansão da terceirização e a permissão para sua utilização inclusive nas atividades-fim, tem-se o aumento das taxas de desemprego e a redução dos salários dos trabalhadores terceirizados. Com isso, há o comprometimento dos direitos e das garantias asseguradas pelo artigo $7^{\circ}$ da Constituição Federal de 1988.

\title{
4 As alterações no mundo do trabalho
}

Entretanto, além da terceirização, os avanços tecnológicos e a expansão dos sistemas de comunicação foram responsáveis por grandes alterações no sistema produtivo. Para Antunes (2013), o mundo do trabalho foi afetado com bastante intensidade por uma série de transformações, principalmente a partir da década de 1980, a qual considera "uma década de grande salto tecnológico, a automação, a robótica e a microeletrônica invadiram o universo fabril, inserindo-se e desenvolvendo-se nas relações de trabalho e de produção do capital". Os novos processos do trabalho foram marcados pela substituição da produção em série e em massa pela flexibilização da produção (ANTUNES, 2013).

E, juntamente com a flexibilização, observou-se a precarização das condições de trabalho, como a extensão da jornada e a redução dos salários, o que desvela a ineficácia do direito social do trabalho, que garante uma jornada de trabalho razoável, acompanhada de um salário equivalente. Nesse sentido, é interessante o que afirma Engels (2014) acerca daquilo que chama de salário justo por uma jornada justa. Jornada justa é aquela que "por su duración 
y intensidad no priva al obrero [...], de la capacidad de realizar la misma cantidad de trabajo al dia seguiente y en los sucesivos" 3(ENGELS, 2014, p. 277).

No caso do salário justo, entendia que

Salario justo, en condiciones normales, es la suma precisa para assegurar al obrero los médios de subsistência necessários, de conformidade con el nível de vida dentro de su situación y la del país, para conservar su capacidade de trabajo y para propagar su espécie ${ }^{4}$ (ENGELS, 2014, p. 276).

Assim, a combinação de jornada e salário deve ser condizente com a consecução dos demais direitos fundamentais. As jornadas exaustivas são prejudiciais à saúde, física e mental, dos trabalhadores. Os salários baixos, por sua vez, impõem aos trabalhadores a necessidade de complementação de renda e, consequentemente, com o aumento do número de horas trabalhadas. Como consequência, há o comprometimento da qualidade de vida e a violação dos direitos fundamentais garantidos pelo ordenamento jurídico.

O desenvolvimento das tecnologias e a sua utilização pelos meios produtivos representa um avanço significativo. No entanto, trouxe consigo um grande paradoxo, pois tanto podem servir para melhorar as condições de trabalho como para criar novas formas de subordinação e exploração da força de trabalho humana. Brynjolfsson (2014) alerta que, apesar do aumento radical da capacidade produtiva da economia, a tecnologia não beneficia automaticamente todo mundo. Ao contrário, as rendas e as oportunidades de emprego tem se tornado mais desiguais.

As mudanças tecnológicas observadas no século XXI não se comparam àquelas provocadas pelo motor a vapor, o motor elétrico e o motor de combustão. As tecnologias digitais desempenham tarefas mentais que eram de domínio exclusivo dos humanos (BRYJOLFSSON,2014). Essa mudança implica em novas formas de execução dos contratos de trabalho, o que, por sua vez, implica na necessidade de um novo perfil de trabalhador. $\mathrm{O}$ domínio da tecnologia digital pode, nesse cenário, se tornar um fator de exclusão de parcela significativa de trabalhadores do mercado de trabalho. Com mais trabalhadores excluídos do mercado formal de trabalho, maiores as chances de precarização do trabalho.

Schwab (2016) enfatiza que a revolução tecnológica provocará mais agitações que as anteriores. Isso porque tudo acontece num ritmo muito mais rápido, há muitas mudanças radicais e profundas ocorrendo simultaneamente, o que provoca a transformação completa dos

\footnotetext{
3 "por sua duração e intensidade não priva o trabalhador [...] da capacidade de realizar a mesma quantidade de trabalho no dia seguinte e em sucessivos" (ENGELS, 2014, p. 277, tradução nossa).

4 "Salário justo, em condições normais, é a soma precisa para assegurar ao trabalhador os meios de subsistência necessários, de acordo com o nível de vida dentro da sua situação e a do país, para conservar sua capacidade de trabalho e para propagar a sua espécie”. (ENGELS, 2014, p. 276, tradução livre)
} 
sistemas anteriores. Apesar "do potencial impacto positivo da tecnologia no crescimento econômico, é essencial, contudo, abordar o seu possível impacto negativo, pelo menos a curto prazo, no mercado de trabalho" (SCHWAB, 2016, p. 41).

A quarta revolução industrial criou novas indústrias e novos modelos de produção. Por essa razão, Schwab (2016, p. 43), faz o seguinte alerta:

\begin{abstract}
Diferentes categorias de trabalho, particularmente aquelas que envolvem o trabalho mecânico repetitivo e o trabalho manual de precisão, já estão sendo automatizados. Outras categorias seguirão o mesmo caminho, enquanto a capacidade de processamento continuar a crescer exponencialmente. Antes do previsto pela maioria, o trabalho de diversos profissionais diferente poderá ser parcial ou completamente automatizado [...].
\end{abstract}

Por outro lado, há quem defenda que a partir da nova estruturação dos modelos de produção, o trabalho assumirá uma nova centralidade. Gald (2018) assevera que a Indústria 4.0, nascida entre 2013 e 2016, distingue-se das fases anteriores porque insere um novo componente dentre os fatores relacionados ao modo de produção inaugurando a era do conhecimento. Contemporaneamente, todos os saberes e conhecimentos acumulados estão acessíveis, via internet, influindo diretamente no soerguimento da cidadania e na inserção produtiva de trabalhadores aptos a operar as mídias sociais como ferramentas de trabalho.

Nessa perspectiva, a quarta revolução industrial - ou Indústria 4.0 - está transformando o panorama industrial, assentada principalmente na combinação de tecnologias avançadas e a internet. Pode-se utilizar o termo Indústria 4.0 para descrever a estratégia de alta tecnologia promovida inicialmente na Alemanha e que abrange um conjunto de tecnologias de ponta ligadas à internet com objetivo de tornar os sistemas de produção mais flexíveis e colaborativos (SANTOS et al., 2018, p. 112).

Apesar de estar praticamente consolidada, a Indústria 4.0, enquanto resultado de diversos processos históricos que se configuraram nas revoluções industriais, ainda gera dúvidas e desafios, especialmente no âmbito do mundo do trabalho. O novo modo de produção, resultado da quarta revolução industrial, é caracterizado pelo surgimento de fábricas inteligentes e pelo sistema de produção flexível, a partir do uso de tecnologias da informação e da comunicação, da inteligência artificial e da robotização de determinadas etapas da produção.

A produção no ambiente da Indústria 4.0 implica em mudanças profundas na organização do trabalho. E para atender a flexibilidade necessária para o fornecimento de produtos mais individualizados e com custos reduzidos, os trabalhadores passam a ter uma importância estratégica. Assim, as “organizações podem fomentar a criatividade e habilidades 
dos trabalhadores utilizando as máquinas para a realização de tarefas monótonas e repetitivas ou de difícil ergonomia e assim, aproveitar os pontos fortes de cada um" (SANTOS et al., 2018, p. 120). Por outro lado, é necessário pensar em novas interfaces homem-máquina, de modo a permitir que novos modos de interação, como comandos baseados em voz ou o reconhecimento de gestos, sejam adaptados às novas restrições de trabalho (SANTOS et. al, 2018).

Nessa perspectiva, o trabalho assume um novo protagonismo e abre-se um universo de possibilidades ainda desconhecidas. Entretanto e ao mesmo tempo, uma parcela significativa de trabalhadores ficará de fora desse novo mercado de trabalho, porque não conseguirá se inserir. Ademais, mesmo aqueles que passarem a ocupar e a desenvolver as novas formas de trabalho, não terão garantia de que farão jus a um trabalho remunerado adequadamente, com jornadas de trabalho que permitam o lazer e o descanso, tampouco que permanecerão no mercado.

Essa mesma preocupação é compartilhada por Kaplan (2016, p. 1959), que alerta para os efeitos acelerados das recentes mudanças:

L'effetto accelerato dei recenti progressi nel campo dell'intelligenza artificiale sul cambiamento tecnologico confonderà i mercati del lavoro in due modi. Il primo è la pura veritá che l'automazione rimpiazzerà i lavoratori, eeliminando i lor impieghi. Questo significa meno posti di lavoro. [...] Ma la seconda minaccia è molto più sottile e difficile da predire. Molti miglioramenti tecnologici cambiano le regole del gioco permettendo alle imprese di riorganizzarsi e riprogettare il modo in cui lavorano. ${ }^{5}$

Os melhoramentos na organização e nos processos tornarão não só os empregos obsoletos, mas também as habilidades. Assim, um caixa será demitido quando o banco instalar caixas eletrônicos, criando-se a necessidade de contratar mais engenheiros de rede e não caixas. Mesmo aumento a força de trabalho, não haveria necessidade de contratação de mais caixas. Do mesmo modo, tecelões poderiam aprender a operar nos teares e os jardineiros a realizar a manutenção dos cortadores de grama. No entanto, a aquisição de novas habilidades não acontece da noite para o dia. Com isso, os trabalhadores supérfluos, aqueles que estão à margem do modo de produção e que estão sem trabalho, não conseguem se adaptar e ficarão à margem do mercado de trabalho (KAPLAN, 2016).

\footnotetext{
5 “O efeito acelerado dos recentes avanços na inteligência artificial sobre a mudança tecnológica confundirá os mercados de trabalho de duas maneiras. A primeira é a pura verdade de que a automação substituirá os trabalhadores e substituirá seus empregos. Isso significa menos postos de trabalho. [...] Mas a segunda ameaça é muito mais sutil e difícil de prever. Muitas melhorias tecnológicas mudam as regras do jogo, permitindo às empresas reorganizar e redesenhar o modo como trabalham.” (KAPLAN, 2016, p. 1959, tradução nossa).
} 
Como aconteceu nas revoluções industriais anteriores, novos processos, produtos e modelos de negócios surgirão e, como consequência, provocarão grandes impactos sociais, econômicos e tecnológicos (SANTOS et. al., 2018). As mudanças decorrentes das inovações e avanços tecnológicos e os rearranjos nos sistemas produtivos podem provocar, portanto, alterações no mundo do trabalho que terão, como consequência, a exclusão de parcelas significativas dos trabalhadores do mercado formal de trabalho. Isso porque as exigências impostas pelo novo modo de produção requerem um profissional com características diversas, como dominar idiomas, entender de tecnologia, saber se relacionar, ser proativo, estar em permanente formação.

\section{Os entraves à efetivação do direito social ao trabalho na contemporaneidade}

Ainda que num primeiro momento não sejam sentidos de modo tão impactante os efeitos imediatos da quarta revolução industrial no âmbito laboral, a longo prazo os mesmos surtirão efeitos e afetarão não apenas as relações de emprego propriamente ditas, mas também o mundo do trabalho. Assim, poderão representar mais um entrave à efetivação do direito social ao trabalho.

A reestruturação do sistema produtivo provoca pelo menos num primeiro momento, a precarização do trabalho e do emprego. Maeda (2017, p. 46-47) afirma que a primeira forma de precarização do trabalho é resultado direto da reestruturação produtiva, que se verifica nos modelos de contratos atípicos, como o contrato temporário, a subcontratação ou o contrato a tempo parcial. Já a precarização do emprego também é decorrente das reestruturações flexíveis que afastam o trabalhador do seu real empregador, como ocorre na subcontratação por meio da terceirização, da quarteirização ou da pejotização.

Entretanto, à margem das mudanças no mundo do trabalho, duas situações extremamente gravosas e que afetam diretamente a efetivação do direito social ao trabalho permanecem: a desigualdade de gênero e o trabalho em condição análoga ao de escravo. Identificou-se que em ambas as situações há violações aos direitos fundamentais do trabalho, bem como aos dispositivos legais, nacionais e internacionais. A desigualdade de gênero, como se verá na sequência, afeta não apenas as possibilidades de ingresso no mercado de trabalho, mas também a remuneração e a ascensão na carreira, contrariando o que dispõem as Convenções n. 100 e n. 111, ambas da Organização Internacional do Trabalho, de 1951 e 1958, respectivamente. A primeira trata da Igualdade de Remuneração e a segunda sobre a Discriminação no emprego e profissão e ambas foram ratificadas pelo Brasil. 
Além destas, outros instrumentos normativos foram editados: a Convenção n. 156, de 1981, sobre a igualdade de oportunidade e de tratamento para trabalhadores e trabalhadoras com responsabilidades familiares e a Convenção n. 183, de 2000, sobre a proteção da maternidade. O Brasil não ratificou essas duas convenções, o que demonstra que ainda há um longo caminho a percorrer no sentido de superar os índices e estatísticas que comprovam a persistência da desigualdade de gênero no mercado de trabalho.

Em relação ao trabalho escravo, as Convenções n. 29, de 1930, sobre o trabalho forçado e a Convenção n. 105, de 1957, sobre a abolição do trabalho forçado, ambas da Organização Internacional do Trabalho, foram ratificadas pelo Brasil e estão em vigor no ordenamento interno. Entretanto, sistematicamente são identificadas inúmeras situações de trabalhadores em situação análoga a de escravo, violando os preceitos básicos do trabalho digno e do trabalho decente.

De todo modo, tanto uma quanto outra forma de violação remontam a tempos remotos e tem nas suas origens a atribuição de valor que é decorrência das funções sociais de uma mercadoria. A produção de uma mercadoria demanda investir ou incorporar a ela determinada quantidade de trabalho, mas não qualquer trabalho, e sim o trabalho social. Ou seja, a produção de um bem para uso pessoal e direto resulta num produto, não numa mercadoria (ANTUNES, 2013, p. 62).

Nesse sentido, é pertinente a contribuição de Marx (2013, p. 578) quando refere que "a produção capitalista não é apenas a produção de mercadorias, mas essencialmente produção de mais-valor", na medida em que o trabalhador não produz mais para si, mas sim para o capital. Desse modo, o trabalhador produtivo é aquele que produz mais valor ao capital. Marx (2013) alerta que somente é produtivo aquele trabalhador que produz mais-valor ou que serve para a valorização do capital. Assim, o trabalho da mulher, que inicialmente foi em prol do grupo familiar, permanece sendo valorizado de modo diferente.

Por outro lado, Sandberg (2013) ressalta que no âmbito laboral as decisões mais importantes ainda são decididas pelos homens. Isso ocorre tanto no âmbito público quanto privado. No caso brasileiro, as "mulheres ocupam aproximadamente 14\% dos cargos executivos nas quinhentas maiores empresas do país. Na América Latina [...] 1,8 das maiores empresas tem mulheres na direção executiva" (SANDBERG, 2013 p. 18).

A desigualdade de gênero é percebida em vários aspectos. Um relatório do Fórum Econômico Mundial que analisou 149 países, apontou que o número de mulheres que ingressam no mercado formal de trabalho é menor do que o de homens; que a participação das 
mesmas na política e em cargos mais elevados é inferior à masculina; que no setor de inteligência artificial, por exemplo, a presença é irrisória.

No Brasil, dados da Pesquisa Nacional por Amostra de Domicílio (PNAD) apontam que em termos salariais, a diferença é significativa: em média, mulheres ganham o equivalente a 2/3 (76\%) do que ganham os homens, desenvolvendo as mesmas funções, ainda que as mesmas trabalhem três horas a mais por semana. Em relação ao número de horas trabalhadas, a pesquisa aponta que entre horas de trabalho remunerado, cuidados com membros da família e afazeres domésticos, as mulheres trabalham, em média, 54,4 horas por semana, enquanto os homens trabalham 51,4 horas semanais.

Outro indicativo acerca do salário diz respeito ao número de filhos: mulheres sem filhos recebiam, no último trimestre de 2018 , em média $\mathrm{R} \$ 2.182,06$, enquanto as com filhos recebiam cerca de $R \$ 1.618,47$, sendo que aquelas com mais de três filhos ganhavam $R \$$ 1.426,53, em média (IBGE, 2018).

De modo muito semelhante ao que ocorre com a desvalorização do trabalho da mulher, o trabalho em condição análoga ao de escravo demonstra que a atribuição de valor a determinado produto, também está condicionada àquele que a produz. Também chamado de escravidão contemporânea, o trabalho em condição análogo ao de escravo é uma das formas mais violentas de afronta aos direitos fundamentais. Ainda que formalmente abolida em 1988, a escravidão continua presente na contemporaneidade.

E aqui cabe um breve registro acerca de uma questão conceitual importante. No Brasil, não há escravidão, desde a sua abolição. O Código Penal, em seu artigo 149 tipifica o trabalho em condição análoga ao de escravo, dispondo que o mesmo se caracteriza pela submissão a trabalhos forçados, jornadas exaustivas, condições degradantes de trabalho ou pela restrição de locomoção. Inclui-se no rol de situação também a servidão por dívida. Todavia, qualquer que seja a nomenclatura adotada, o resultado é o mesmo: uma grave violação de direitos.

A escravidão não corresponde a um sistema de produção determinado: os escravos trabalharam em minas, foram preceptores dos filhos dos seus senhores, foram cozinheiros. Tanto na economia antiga quanto medieval, no capitalismo comercial e no período industrial, a escravidão esteve presente. E continua presente na atualidade (PÉTRÉ-GRENOUILLEAU, 2009).

Para Brito Filho (2017, p. 41), o trabalho escravo é a antítese do trabalho decente, que "é aquele em que são respeitados os direitos mínimos do trabalhador, necessários à preservação da sua dignidade”. Assim, o desrespeito aos direitos mínimos sujeita o 
trabalhador a condição de trabalho que está abaixo do que é exigido para que seja preservada a sua dignidade.

Corriqueiramente são encontrados trabalhadores e trabalhadoras em condição análoga a de escravo, nas áreas urbanas e rurais, nos mais diversos segmentos econômicos. O que caracteriza a escravidão contemporânea não é apenas a restrição à liberdade ou ao direito de ir e vir. A mesma se caracteriza pelas péssimas condições de trabalho, retenção de documentos, servidão por dívida, remuneração insatisfatória ou inexistente, isolamento geográfico, jornadas exaustivas. Os trabalhadores e trabalhadoras nessas condições têm violados os direitos fundamentais e a própria dignidade, contrariando os preceitos constitucionais.

Nessa perspectiva, o Estado Democrático de Direito deve "possibilitar a igualdade de oportunidades, o mesmo ponto de partida para todos. Como detentor da soberania, deve resgatar e promover a participação ativa dos corpos intermediários da sociedade civil" (GOMES, 2009, p. 147).

Apenas com alguns apontamentos ilustrativos, percebe-se que a igualdade formal e a plena efetivação do direito fundamental ao trabalho não alcançam todas as pessoas. A garantia de efetividade do direito social do trabalho implica, portanto, a adoção de ações e de estratégias capazes de enfrentar as crises econômicas e a reestruturação dos modos de produção, de modo a assegurar o pleno emprego e as mesmas garantias de acesso e permanência no mercado de trabalho.

\section{Conclusão}

O direito do trabalho é um dos mais significativos direitos sociais fundamentais garantidos pelo texto constitucional brasileiro. Entretanto, em termos de efetividade, constatase que é necessário o enfrentamento de questões como o desemprego, o trabalho precário, o trabalho em condições análogas ao de escravo, o trabalho infantil, bem como a desigualdade de gênero no âmbito laboral, que afetam diretamente as condições dignas de trabalho. Ademais, as transformações do mercado de trabalho, especialmente com a chamada indústria 4.0, exigem um novo perfil de trabalhadores, além de estabelecerem novas relações laborais.

Nesse contexto, faz-se necessário analisar as implicações do cenário contemporâneo para a concretização do direito social fundamental do trabalho, assim como refletir sobre as possibilidades e as perspectivas para a implementação de políticas públicas garantidoras desse direito fundamental. Especialmente no cenário contemporâneo, marcado por rupturas 
significativas e alterações no sistema produtivo, faz-se necessário refletir acerca do mundo do trabalho e dos impactos das transformações produtivas nas relações de trabalho e de emprego.

A centralidade do trabalho ocupa diferentes espaços de acordo com as condições sociais, políticas e econômicas de determinadas sociedades. Prova disso são os modos de produção taylorista, fordista e toyotista que marcaram o sistema produtivo capitalista.

Entretanto, ainda que as transformações nos modos de produção e os avanços sociais afetem diretamente o direito social do trabalho, é imprescindível que se compreenda o mesmo em sua acepção mais ampla, especialmente no que diz respeito à sua fundamentalidade. Isso porque é a partir da efetivação do direito social ao trabalho que os demais direitos fundamentais podem ser concretizados.

O cenário contemporâneo, marcado por avanços tecnológicos que modificarão o sistema produtivo de forma nunca antes vista, convive, ao mesmo tempo, com formas arcaicas de afronta aos direitos humanos e fundamentais, como a desigualdade de gênero que se perpetua e o trabalho em condição análoga a de escravo. A conjunção das três situações brevemente apontadas no presente estudo indica a necessidade de dedicar um olhar mais atento e cuidadoso ao mundo do trabalho.

Assim, em resposta ao problema de pesquisa: quais os entraves para a efetivação do direito social ao trabalho na sociedade contemporânea?, constata-se que os entraves para a efetivação do direito social ao trabalho na sociedade contemporânea a partir da perspectiva dos direitos fundamentais são complexos e multifacetários, razão pela qual demandam uma atenção especial. Além das políticas internas de geração de emprego e renda, é necessária a adoção de ações e de estratégias que assegurem o trabalho digno e a remuneração decente.

É preciso ainda considerar as questões que afetam a economia internacional e que refletem no cenário interno. Processos como a globalização e a indústria 4.0 afetam significativamente o modo de produção e provocam alterações no mercado de trabalho. A exigência de novos profissionais, com novas habilidades e competências, implica na adoção de políticas de formação e políticas educacionais condizentes com a nova realidade.

\section{Referências}

ALVES, Giovani. Trabalho e subjetividade: o espírito do toyotismo na era do capitalismo manipulatório. São Paulo: Boitempo, 2011.

ANTUNES, Ricardo. A dialética do trabalho II: escritos de Marx e Engels. São Paulo: Expressão popular, 2013. 
BARBOSA, Vinícius Gozdecki Quirino. A interferência da política neoliberal no direito Fundamental ao trabalho. Revista ESMAT. Ano 9. N. 14, 2017, p. 235-250. Disponível em http://esmat.tjto.jus.br/publicacoes/index.php/revista_esmat/article/view/217/201. Acesso em: 06 abr. 2020.

BRITO FILHO, José Claudio Monteiro de. Trabalho decente: análise jurídica da exploração do trabalho: trabalho escravo e outras formas de trabalho indigno. 4. ed. São Paulo: LTr, 2016.

BRYNJOLFSSON, Erik; McAFEE, Andrew. Novas tecnologias versus empregabilidade. São Paulo: M. Books do Brasil Editora Ltda, 2014.

DELGADO, Mauricio Godinho. Curso de direito do trabalho. 13. ed. São Paulo: LTr, 2014.

DURKHEIM, Émile. Da Divisão do Trabalho Social. Tradução Eduardo Brandão. 4. ed. São Paulo: Martins Fontes, 2010.

ENGELS, Friedrich. El papel del trabajo en la transformación del mono en hombre y otros textos. Ciudad Autônoma de Buenos Aires: EGodot Argentina, 2014.

GALD, Will. Indústria 4.0: riqueza, cidadania e estado. 1. ed. Washington, USA: Editora Amazon, 2018.

GOMES, D. G. P. Crise financeira e a valorização do trabalho humano. Revista LTr,. São Paulo, v. 73, n. 2, fev. 2009.

HEGEL, G.W.F. Fenomenologia do Espírito. 2. ed. Rio de Janeiro: Vozes, 1992.

HOBSBAWN, Eric J. A era do capital: 1848 - 1875. São Paulo: Paz e Terra, 1979.

IBGE. Pesquisa Nacional por amostra de domicílio. 2018. Disponível em https://www.ibge.gov.br/estatisticas-novoportal/sociais/trabalho/9173-pesquisa-nacional-poramostra-de-domicilios-continua-trimestral.html?=\&t=o-que-e. Acesso em: 06 abr. 2020.

KAPLAN, Jerry. Le persone non servono: lavora e ricchezza nell'epoca dell'inlligenza artificiale. Roma: Luiss University Press, 2016.

LINDEN, Marcel Van Der. Trabalhadores do mundo: ensaios para uma história global do trabalho. Tradução Patrícia de Queiroz Carvalho Zimbres. Campinas, SP: Editora da Unicamp, 2013.

MAEDA, Patrícia. A era dos zero direitos - trabalho decente, terceirização e contrato zerohora. São Paulo: LTr, 2017.

MARX, Karl. O capital: crítica da economia política. Livro 1. Rio de Janeiro: Nova Cultural, 1996, vol. 2.

MARX, Karl. O capital: crítica da economia política. Livro I: O processo de produção do capital. Tradução de Rubens Enderle. São Paulo: Boitempo, 2013. 
PÉTRE-GRENOUILLEAU, Olivier. A história da escravidão. Tradução Mariana Echalar. São Paulo: Boitempo, 2009.

ROMITA, Arion Sayão. Direitos fundamentais nas relações de trabalho. São Paulo: LTr, 2007.

SANDBERG, S. Faça acontecer: mulheres, trabalho e a vontade de liderar. São Paulo: Companhia das Letras, 2013.

SANTOS, B. P.; ALBERTO, A.; LIMA, T. D. F. M.; CHARRUA-SANTOS, F. M. B. Indústria 4.0: desafios e oportunidades. Revista Produção e Desenvolvimento. v.4, n.1. Rio de Janeiro, 2018, p.111-124. Disponível em http://revistas.cefetrj.br/index.php/producaoedesenvolvimento/article/view/316. Acesso em: 07 abr. 2020.

SARLET, Ingo Wolfgang. A eficácia dos direitos fundamentais: uma teoria dos direitos fundamentais na perspectiva da Constituição. 10. ed. Porto Alegre: Livraria do Advogado, 2010.

SCHWAB, Claus. A quarta revolução industrial. Tradução Daniel Moreira Miranda. São Paulo: Edipro, 2016.

SILVA, Isis Almeida; BENACCHIO, Marcelo. Ponderações entre o capitalismo humanista e a lógica de mercado globalizado: a fraternidade como agente econômico. In: Prisma Jurídico. v. 18, n. 1, São Paulo, jan./jun. 2019, p. 48-63. Disponível em

https://periodicos.uninove.br/index.php?journal=prisma\&page=issue \&op=view\&path\%5B $\% 5$ $\underline{\mathrm{D}=650}$. Acesso em: 27 maio 2020.

SÜSSEKIND, A. Direitos fundamentais na relação de trabalho. Revista de Direito do Trabalho, São Paulo, ano 32, n. 123. jul./set. 2006.

VIANNA, S. et al. Instituições de direito do trabalho. 2. ed. São Paulo: LTr, 2004. v. 1.

WEBER, Max. A Ética Protestante e o Espírito do Capitalismo. Tradução José Marcos Mariane de Macedo. São Paulo: Companhia das letras, 2004. 